\title{
Trabalho docente em tempos de pandemia: mais um retrato da desigualdade educacional brasileira
}

\author{
Teaching work in times of pandemic: \\ another portrait of Brazilian educational inequality
}

\section{Labor docente en tiempos de pandemia:} otro retrato de la desigualdad educativa brasilera

DALILA ANDRADE OLIVEIRA*

Universidade Federal de Minas Gerais, Belo Horizonte-MG, Brasil. EDMILSON ANTONIO PEREIRA JUNIOR ${ }^{* *}$ Universidade Federal de Minas Gerais, Belo Horizonte-MG, Brasil.

\begin{abstract}
RESUMO: O artigo apresenta resultados de pesquisa sobre o trabalho docente e a educação básica com a pandemia do coronavírus (Covid19). Expõe aspectos operacionais e metodológicos da pesquisa com 15.654 professores das redes públicas de ensino do país e cujos dados foram coletados por meio de formulário eletrônico. O texto traz informações sobre o suporte institucional oferecido pelas redes de ensino e os recursos tecnológicos de professores e estudantes para desenvolver as atividades. Aborda, ainda, a carga de trabalho dos professores e a participação dos estudantes nas atividades. Dentre os resultados obtidos, destacam-se a significativa variação de condições entre redes públicas de ensino e a relativa sobrecarga de trabalho dos professores.

Palavras-chave: Condições do trabalho docente. Ensino remoto. Pandemia.
\end{abstract}

* Doutora em Educação pela Universidade de São Paulo. É professora da Universidade Federal de Minas Gerais e, atualmente, professora visitante do Programa de Pós-Graduação em Educação da Universidade Federal da Paraíba. Coordena o Grupo de Estudos sobre Política Educacional e Trabalho Docente (GESTRADO). Pesquisadora PQ1A/CNPq. E-mail: <dalilaufmg@yahoo.com.br>.

** Mestre em Sociologia e Doutor em Educação pela Universidade Federal de Minas Gerais, mesma instituição na qual atualmente é Pós-doutorando na Faculdade de Educação. É estatístico do Grupo de Estudos Sobre Política Educacional e Trabalho Docente (GESTRADO). E-mail:<edmilsonpj@yahoo.com.br>. 


\begin{abstract}
The article presents research results on teaching work and basic education with the coronavirus pandemic (Covid-19). It exposes operational and methodological aspects of the research with 15,654 teachers from public schools in the country whose data were collected through an electronic form. The text provides information about the institutional support offered by the educational networks, and the technological resources of teachers and students to develop the activities. It also addresses teachers' workload and the students' participation in activities. Among the results obtained, we highlight the significant variation in conditions between public schools, and the relative work overload of teachers.
\end{abstract}

Keywords: Teaching work conditions. Remote teaching. Pandemic.

RESUMEN: El artículo presenta los resultados de la investigación sobre la labor docente y la educación básica con la pandemia del coronavirus (Covid-19). Expone aspectos operativos y metodológicos de la investigación con 15,654 docentes de escuelas públicas del país cuyos datos fueron recolectados mediante un formulario electrónico. El texto informa sobre el apoyo institucional que brindan las redes educativas y los recursos tecnológicos de docentes y estudiantes para desarrollar las actividades. También aborda la carga laboral de los profesores y la participación de los estudiantes en las actividades. Entre los resultados obtenidos, destacamos la significativa variación de condiciones entre las escuelas públicas y la relativa sobrecarga de trabajo de los docentes.

Palabras clave: Condiciones laborales docentes. Enseñanza remota. Pandemia.

\title{
Introdução
}

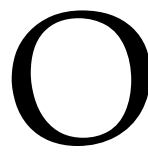

ano letivo escolar no Brasil iniciou em fevereiro e, cerca de um mês depois, o ensino presencial nas escolas foi suspenso para conter a propagação do coronavírus (COVID-19). A doença foi declarada como pandemia pela Organização Mundial da Saúde (OMS) e impôs medidas restritivas de circulação às pessoas, tendo afetado diretamente diversos setores em todo o mundo, entre os quais a educação.

A imprevisibilidade da pandemia e a celeridade de implementação das medidas de distanciamento social demandaram dos sistemas educacionais alternativas para o desenvolvimento de atividades escolares remotas. Inexistia, até aquele momento, qualquer tipo 
de planejamento das redes de ensino para lidar com isso. Afinal, realizar atividades educacionais não presenciais exige dos professores e dos estudantes recursos tecnológicos e conhecimentos específicos para manejá-los. As redes públicas de ensino se esforçaram para oferecer suporte institucional para facilitar a execução das novas práticas de ensino.

Com a mesma rapidez com que as adaptações foram implementadas pelas redes e instituições de ensino, os grupos de pesquisa foram compelidos a lançar mão de estratégias de pesquisa ágeis e apropriadas ao contexto para avaliar empiricamente as condições de oferta da educação e, em especial, o trabalho docente. Nessa premência, a pesquisa Trabalho Docente em Tempos de Pandemia foi desenvolvida para conhecer os efeitos das medidas de distanciamento social em função da pandemia da Covid-19 sobre o trabalho dos(as) professores(as) de educação básica nas redes públicas de ensino no Brasil.

Como se não bastasse, a pandemia ocorreu em um momento bastante particular da vida política brasileira e, especialmente, da agenda educativa. O Brasil chegou ao século XXI com uma dívida social muito grande com amplos setores da sociedade e com uma das mais injustas divisões de riquezas no mundo.

Apesar das políticas implementadas nos 13 anos dos governos Lula (2003-2010) e Dilma Rousseff (2011-2016), que promoveram significativa inclusão de segmentos historicamente vulneráveis da sociedade brasileira no sistema educacional, o pleno direito à educação para a maioria da população ainda é uma dívida a ser paga. O Brasil continua sendo extremamente desigual, localizado na região mais desigual do planeta, a América Latina. Ele ocupa a sétima posição entre os mais desiguais do mundo, conforme aponta o Relatório de 2019 do Programa das Nações Unidas para o Desenvolvimento (PNUD, 2019). O Relatório também alerta para o fato de que o Brasil caiu uma posição no Índice de Desenvolvimento Humano (IDH) - que mede o progresso de uma nação a partir das dimensões renda, saúde e educação -, passando da 78ª para a 79ª posição, em comparação a 2017, no ranking com 189 países. Se considerarmos somente a América do Sul, o Brasil ocupa a quarta posição, ficando atrás de Chile, Argentina e Uruguai. A escolaridade da população brasileira é baixa, sendo que mais da metade da população com 25 anos ou mais concluiu somente o ensino fundamental; e, entre os jovens com idade de 18 a 24 anos, apenas 21,3\% se encontram matriculados na educação superior.

É importante sublinhar, no início desta discussão, a desigualdade persistente que a pandemia evidenciou e aprofundou ainda mais. Algumas informações servem como uma pequena amostra do quanto o País estava pouco preparado para enfrentar uma situação pandêmica que exige o distanciamento social e a realização do trabalho e dos estudos em casa.

Sobre as desigualdades na educação, destaca-se a notável fragmentação da oferta escolar, quando tomamos um dos aspectos mais importantes para assegurar boas condições de ensino: a infraestrutura das escolas. Aos mais pobres são oferecidas escolas mais pobres, ou seja, condições mais precárias de oferta educativa. Ximenes e Agate (2011) 
demonstraram que as escolas com grande concentração de estudantes do Programa Bolsa Família (PBF) e que ofertam a educação integral (Programa Mais Educação) apresentam altos índices de precariedade quando comparadas a outras, cujas famílias dos alunos recebem renda mais alta. Isso mostra que a desigualdade não é prerrogativa somente da distribuição de renda, mas é fato percebido nas condições estruturais das escolas onde estudam aqueles que vivem em situação de pobreza. Portanto, as condições de oferta da educação remota não são as mesmas para todos. Pelo contrário, elas refletem a oferta desigual dos nossos sistemas escolares em termos de acesso a fatores como recursos tecnológicos, apoio pedagógico, suporte à nutrição, entre outros.

A situação política atual do País acentua as condições desiguais de enfrentamento à pandemia. $\mathrm{O}$ Governo tem se demonstrado incapaz de responder eficientemente às exigências impostas pelas crises sanitária e econômica, aprofundadas com a chegada da pandemia. Desde o golpe de Estado ocorrido em agosto de 2016, quando foi levado a cabo o processo de impeachment da presidenta Dilma Rousseff que colocou Michel Temer, o então vice-presidente, no comando do Governo Federal, foi mudado o rumo do País. A partir desse evento, temos enfrentado uma política de austeridade econômica que compromete a sobrevivência de milhões de brasileiros(as). Um dos feitos mais marcantes foi a aprovação com larga maioria no Congresso Nacional da Emenda Constitucional № 95, que congela o gasto com políticas sociais para os próximos 20 anos.

Os recursos públicos têm sido retirados das áreas sociais para o pagamento de juros da dívida pública que beneficiam os bancos e as empresas privadas. Essas medidas já vinham fragilizando a economia, incrementando ainda mais o desemprego e aumentando o imenso fosso entre ricos e pobres na sociedade brasileira, tendendo a se agravar com as restrições impostas pela pandemia.

Além dos severos cortes nos recursos destinados às políticas sociais nos últimos cinco anos, percebe-se progressivo avanço de movimentos de direita não somente no País, como também em grande parte do mundo. Neste momento, a direita tem conseguido operar por incorporações tradicionais, fazendo ressuscitar velhos jargões e apostando no medo das classes médias com o estímulo ao ódio social, como a homofobia, o machismo, o racismo. A maior expressão desse fenômeno na educação fica visível em projetos como o Escola sem partido e campanhas contra a chamada "ideologia de gênero", no Brasil, ou Con mis hijos no te metas, no Peru, entre outras manifestações em diferentes países, em favor do homeschooling, da choice school e da militarização das escolas (OLIVEIRA, 2020).

Esses programas e campanhas convocam as famílias a garantir uma vigilância ideológica do trabalho escolar, ao mesmo tempo que atacam a autonomia docente. Diante da pandemia, esse quadro se agrava por meio de reações negacionistas e fundamentalistas, como, por exemplo, a ideia de que a pandemia é uma invenção de laboratório ${ }^{1}$ ou que não passa de uma "gripezinha" ${ }^{2}$, até a precarização das condições objetivas de acesso à alimentação, à segurança alimentar, entre outros fatores essenciais a uma vida digna. 
Assim, o País retoma a velha tradição de condenar a diversidade à desigualdade, pois as vítimas primeiras dessa situação são os mais pobres e as ditas minorias.

Por fim, a pandemia se instalou entre nós no momento em que estavam para ser votadas a PEC № 15/2015, na Câmara dos Deputados, e a PEC № 26, no Senado Federal, que aprovaram a Emenda Constitucional № 108, sobre o Fundo de Manutenção e Desenvolvimento da Educação Básica e de Valorização dos Profissionais da Educação (Fundeb). O Fundeb é uma das principais fontes de financiamento da educação básica e, como era um fundo temporário, expiraria em 31 de dezembro de 2020. Com a chegada da pandemia, foram suspensas as reuniões das comissões e as votações passaram a ser realizadas exclusivamente no plenário virtual da Câmara Federal. Por meio de um acordo, protagonizado pelo presidente da Câmara Federal, levou-se a plenário essa votação em caráter emergencial. Com muita mobilização, obteve-se a aprovação da Emenda Constitucional № 108, que cria o Fundeb permanente, restando ainda importante disputa em sua regulamentação no sentido de definir, em última instância, os critérios e as finalidades para a destinação dos recursos públicos empregados na educação básica.

O foco do debate acadêmico na área educacional também sofreu mudanças com as restrições impostas pela pandemia. Se antes os estudos sobre as condições de trabalho docente atribuíam um papel central à estrutura das escolas, agora, abre-se espaço para avaliar as condições de moradia e o acesso e utilização de recursos tecnológicos por professores e estudantes. Se antes a existência de laboratórios de informática nas escolas era uma demanda, hoje passa a ser item essencial a disponibilidade de computador com rede de internet adequada nas residências.

A pesquisa acadêmica pode contribuir com o desenvolvimento de conhecimento sobre a nova realidade. Ela pode ser tomada como um caminho para aprimorar as condições em que o ensino se desenvolve, porém, a conexão com a decisão política necessita ser estreitada. Sobre essa associação, Paiva (1998) destacou razões que podem distanciar a pesquisa acadêmica e a decisão política, entre as quais se encontram: a diferença entre os tempos da pesquisa e da política; o fato de que a pesquisa acadêmica tende a não se comprometer com soluções práticas; a existência de visão negativa de que se perde muito tempo e esforço com investigações que, às vezes, não mostram qualquer relevância para o avanço do conhecimento; a dificuldade da lógica do poder em considerar a pesquisa como um espaço de liberdade necessário, útil para a criação e crítica. Contudo, sabemos que as pesquisas têm sido, cada vez mais, usadas para orientar as políticas públicas em geral, e em educação em particular, sendo realizadas na tentativa de buscar evidências que justifiquem determinadas escolhas políticas.

Nesse sentido, esta pesquisa teve o objetivo de conhecer o contexto atual de realização do trabalho docente durante a pandemia, a fim de fornecer subsídios para o diálogo necessário sobre a oferta educativa nessas condições e no retorno às atividades presenciais. Embora movida por essas preocupações, ela não contou com nenhuma fonte direta 
de financiamento. Se por um lado isso não deixa indício de que resultará na formulação de políticas públicas, por outro, garante que todo o rigor acadêmico tenha sido aplicado.

Em meio ao contexto inédito da pandemia, a pesquisa foi planejada e executada para conhecer a nova forma de atuação dos professores da educação básica, verificando como eles estão fazendo para atender às exigências para a realização das atividades de ensino não presenciais. Além das complexas questões pedagógicas relativas ao ensino remoto, buscou identificar as adaptações necessárias à oferta, a disponibilidade de recursos tecnológicos, a sobrecarga de trabalho e a efetividade das aulas a distância.

Os aspectos operacionais e metodológicos da pesquisa e os principais resultados obtidos são discutidos neste texto. A primeira parte descreve a metodologia da investigação e compara características dos professores da amostra e do universo da educação básica pública no Brasil. A segunda aborda as circunstâncias levadas em conta na definição dos métodos utilizados. A terceira apresenta os principais resultados e, em seguida, conclui-se com as considerações finais.

\section{Metodologia da pesquisa}

A pesquisa Trabalho Docente em Tempos de Pandemia objetivou conhecer os efeitos das medidas de distanciamento social impostas pela Covid-19 sobre o trabalho docente na educação básica, buscando elucidar quais atividades estavam sendo desenvolvidas pelos professores e em que condições. O Grupo de Estudos Sobre Política Educacional e Trabalho Docente da Universidade Federal de Minas Gerais (Gestrado/UFMG) foi responsável por definir o desenho metodológico, elaborar o instrumento de coleta de dados, sistematizar e analisar os resultados. Além disso, contou com a parceria da Confederação Nacional dos Trabalhadores em Educação (CNTE) na mobilização dos professores para responderem aos questionários e na divulgação dos resultados.

O universo pesquisado contemplou os professores de educação básica lotados nas redes públicas de ensino municipais, estaduais ou federal de todo o Brasil. Conforme dados do Censo Escolar de 2019, a oferta pública no País possui cerca de 1,7 milhões de professores e 38,7 milhões de estudantes, distribuídos em aproximadamente 139 mil estabelecimentos de ensino.

A coleta de dados foi realizada por meio da plataforma Google Forms, cujo período de preenchimento do questionário pelos professores ocorreu de 8 a 30 de junho de 2020. A divulgação da pesquisa foi feita por meio das mídias sociais do Gestrado, e a CNTE, além da disseminação por esses meios, encaminhou correspondências a todos os sindicatos filiados, solicitando a mobilização dos professores da respectiva base territorial para participar da pesquisa.

A amostra obtida foi de 15.654 professores das redes públicas de ensino. Foram contemplados professores de redes públicas municipais, estaduais e federal com atuação nas 
diferentes etapas e subetapas da educação básica (educação infantil, ensino fundamentalanos iniciais, ensino fundamental - anos finais e ensino médio). Além do ensino regular, a pesquisa abrangeu docentes com inserção nas diferentes modalidades de ensino: educação de jovens e adultos (EJA), educação especial, educação profissional e tecnológica, educação do campo e educação escolar indígena e quilombola. Em relação à distribuição geográfica, a amostra contou com profissionais de todos os estados da Federação.

\section{Perfis da amostra e da população}

A Tabela 1 exibe os perfis dos professores da amostra e do universo pesquisado, observando as variáveis dependência administrativa da rede de ensino em que se encontram lotados, (sub)etapa(s) da educação básica em que atuam e região geográfica. Considerando que não houve controle a priori da quantidade de respondentes de cada subgrupo de professores, tal comparação permite identificar se houve alguma tendenciosidade na cobertura da amostra.

Em relação à dependência administrativa, a distribuição da amostra apresentou uma sobrerrepresentação dos professores das redes estaduais de ensino (Tabela 1). Ao mesmo tempo, a proporção de docentes lotados em redes municipais de ensino encontrada na amostra foi inferior à encontrada no universo de professores da educação básica.

A distribuição da amostra (20,8\%) apresentou uma proporção inferior de professores da educação infantil do que o universo pesquisado (33,1\%) (Tabela 1). Nas demais etapas e subetapas, a amostra apresentou maiores proporções de professores. Isso ocorre devido ao fato de ter sido mais comum, na amostra, a ocorrência de professores que atuam em múltiplas etapas ou subetapas da educação básica.

Em se tratando de região geográfica, houve uma sobrerrepresentação da amostra de professores do Nordeste e do Centro-Oeste do País e uma sub-representação de docentes do Sudeste (Tabela 1) - o oposto do que foi registrado em outras pesquisas com professores no período da pandemia (FCC, 2020; INSTITUTO PENÍNSULA, 2020).

\section{Tabela 1: Comparação das distribuições da amostra e do universo de acordo com as características dos professores da educação básica}

\begin{tabular}{l|l|l|l|l}
\hline Característica & Amostra & \multicolumn{3}{l}{ Universo } \\
\hline Dependência administrativa & Frequência & $\%$ & Frequência & $\%$ \\
\hline Federal & 209 & 1,3 & 36.829 & 2,1 \\
\hline Estadual & 7.807 & 49,9 & 656.006 & 37,9 \\
\hline Municipal & 9.347 & 59,7 & 1.139 .452 & 65,9 \\
\hline
\end{tabular}




\begin{tabular}{|c|c|c|c|c|}
\hline \multicolumn{5}{|l|}{ Etapa da educação básica } \\
\hline Educação Infantil & 3.253 & 20,8 & 571.941 & 33,1 \\
\hline Ensino Fundamental (anos iniciais) & 5.979 & 38,2 & 595.035 & 34,3 \\
\hline Ensino Fundamental (anos finais) & 6.623 & 42,3 & 612.219 & 35,4 \\
\hline Ensino Médio & 5.332 & 34,1 & 374.571 & 21,7 \\
\hline \multicolumn{5}{|l|}{ Região geográfica } \\
\hline Norte & 1.409 & 9,0 & 172.677 & 10,0 \\
\hline Nordeste & 5.471 & 34,9 & 505.026 & 29,2 \\
\hline Centro-Oeste & 2.732 & 17,5 & 132.713 & 7,7 \\
\hline Sudeste & 3.563 & 22,8 & 649.970 & 37,6 \\
\hline Sul & 2.479 & 15,8 & 270.295 & 15,6 \\
\hline
\end{tabular}

Fontes: Amostra: Banco de dados da pesquisa Trabalho Docente em Tempos de Pandemia (GESTRADO, 2020); Universo: Censo Escolar da Educação Básica 2019 (INEP, 2020). Os totais extrapolam 100\% devido ao fato de que um professor pode atuar em mais de uma dependência administrativa ou etapa da educação básica. Apesar de serem poucos casos, nos dados referentes ao universo, o professor pode atuar em escolas de diferentes regiões geográficas.

\section{Aspectos operacionais e metodológicos}

Esta seção traz à tona algumas decisões metodológicas e operacionais exigidas no cenário de pandemia da Covid-19, que impôs uma série de medidas restritivas de circulação de pessoas. Os sistemas escolares tiveram repentinamente que suspender as aulas presenciais e se estruturar para oferecer atividades remotas de ensino e os pesquisadores necessitaram estar atentos ao novo contexto para desenvolver a pesquisa.

Na cronologia dos fatos, em meados de março deste ano, houve o fechamento compulsório das escolas devido à restrição de circulação de pessoas imposta pela Covid-19. Menos de um mês depois, o corpo de pesquisadores do Gestrado se mobilizou para delinear uma pesquisa que captasse como as redes de ensino estavam se adaptando para oferecer atividades remotas e verificar em quais condições os docentes as estavam cumprindo. E, após menos de dois meses de trabalho, a pesquisa iniciou o período de coleta de dados.

Diante do contexto da pandemia e do prazo exíguo de planejamento das atividades da pesquisa, alguns contornos metodológicos seguem mais bem detalhados adiante: 
Figura 1: Linha do tempo dos acontecimentos relacionados à Covid-19 e às atividades da pesquisa

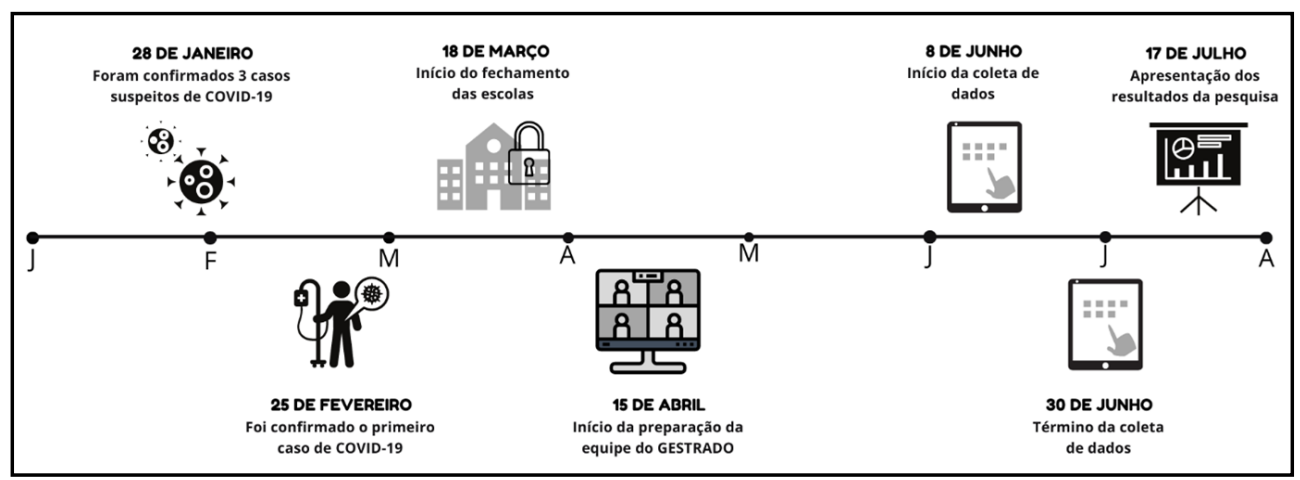

Fonte: Elaborado pelos autores.

\section{Contato com os professores}

O primeiro impasse foi definir a forma de contato com os professores, pois, devido ao distanciamento social, entrevistá-los pessoalmente foi uma opção descartada. Essa alternativa colocaria em risco a saúde dos professores e, também, dos pesquisadores.

Adiciona-se o fato de que era inviável planejar qualquer atividade que demandasse o deslocamento de pesquisadores, mesmo que se desconsiderasse o cenário de isolamento social. O motivo é que a pesquisa não contou com financiamento de nenhuma agência de fomento ou instituição parceira.

A pandemia interrompeu a sequência de outros trabalhos de grande abrangência desenvolvidos pelo Gestrado, dada a suspensão momentânea de algumas atividades nas universidades, assim como nas escolas de redes públicas, campo de pesquisa em desenvolvimento pelo grupo. Entretanto, a equipe não deixou de trabalhar remotamente e abraçou a proposta desta pesquisa. Na busca por uma estratégia de coleta de dados que não exigisse o contato direto entre pesquisado e pesquisador, o contato por telefone figurou como uma opção; porém, não se dispunha de listagem de contato dos professores.

Diante das limitações, a opção foi desenvolver um formulário eletrônico para a coleta de dados que pudesse ser disseminado ao máximo possível de professores da educação básica. Essa tarefa foi favorecida pela disponibilidade de plataformas gratuitas, como é o caso do Google Forms. Ao comparar com outras formas de coleta de dados, como é o caso da entrevista pessoal e por telefone, o preenchimento on-line possui a maior taxa de abandono dos participantes. Para evitá-lo, os pesquisadores estabeleceram um instrumento de coleta de dados adequado ao formato eletrônico, impedindo ao máximo que o professor comece a responder e interrompa o preenchimento sem finalizar o questionário. Desse 
modo, o questionário foi constituído somente por questões fechadas e a sua extensão foi controlada para que o preenchimento não tomasse muito tempo.

O fato de não se ter o controle da quantidade e da definição do público participante da pesquisa incide no desenho de amostragem, como explicado adiante.

\section{Desenho de amostragem}

O fato de não se ter uma listagem dos professores para se extrair uma amostra e por inexistir uma definição da quantidade de elementos a serem pesquisados caracteriza o método de amostragem não probabilístico. É diferente da amostragem probabilística, em que geralmente se utiliza uma listagem (sampling frame) de todas as unidades amostrais da população que permite selecionar a amostra sem vícios de seleção. Também é possível conhecer as probabilidades de seleção de cada elemento da amostra, o que permite realizar os cálculos necessários para fazer inferências sobre a população estudada (BABBIE, 2004).

O método não probabilístico de amostragem não permite estimar os parâmetros da população, atribuindo a margem de erro e o nível de significância da amostra. Entretanto, os dados obtidos permitem conhecer a realidade do conjunto de participantes da pesquisa. Em nosso caso, os professores apresentam características que abrangem as diferentes configurações relacionadas à localização geográfica, à etapa de atuação na educação básica e à dependência administrativa das escolas.

Algumas ações contribuíram com a qualidade dos dados obtidos. Por não existir uma definição prévia da quantidade de respondentes, a informação sobre a realização da pesquisa deveria chegar ao maior número possível de professores e, consequentemente, contar com uma adesão satisfatória para preenchimento do questionário. Por esse motivo, reforça-se a importância da parceria com a CNTE, que promoveu ações de divulgação da pesquisa e de mobilização dos professores para responderem ao questionário.

Outro fator importante foi o monitoramento ao longo do período de coleta de dados, que ocorreu de 8 a 30 de junho, em que a equipe de pesquisadores acompanhou os quantitativos de respondentes de acordo com o estado da federação, o tipo de rede pública e a etapa da educação básica. Ao observar uma baixa quantidade de respondentes, por exemplo, em determinada unidade federativa, a CNTE era informada e entrava em contato com a direção dos sindicatos e parceiros da localidade para solicitar maior empenho para a participação dos professores. Conforme visto anteriormente (Tabela 1), todos os subgrupos de docentes da educação básica foram abrangidos.

\section{Resultados da pesquisa}


Esta seção traz informações dos 15.654 participantes da pesquisa referentes ao suporte institucional oferecido pelas redes de ensino, aos recursos tecnológicos disponíveis a eles e aos alunos para desenvolver as atividades, a sobrecarga de trabalho decorrente da nova modalidade de trabalho e a participação dos estudantes. $\mathrm{O}$ critério para participar na pesquisa era ser professor da educação básica nas redes públicas de ensino, independentemente de estar ou não exercendo alguma atividade de ensino remoto.

Assim, a primeira constatação foi que $84,3 \%$ dos respondentes encontravam-se, no momento de realização da pesquisa, desenvolvendo as atividades de ensino de forma não presencial; enquanto alguns as desenvolviam na própria casa, outros as faziam nas dependências da escola. Isso mostra os diferentes tempos que os sistemas de ensino necessitaram para se adaptar ao ensino remoto, sendo que, decorridos três meses da suspensão das aulas presenciais, 15,7\% não desenvolviam atividades a distância.

As análises a seguir foram delimitadas somente nos respondentes que se encontravam desenvolvendo aulas remotas. Esses professores da educação básica possuem algum nível de experiência na nova modalidade de ensino, permitindo-lhes avaliar aspectos que, talvez, aqueles com suspensão total das atividades sequer conheçam.

\section{Suporte institucional}

As medidas de distanciamento social da população resultaram em mudanças abruptas na forma do desenvolvimento das atividades docentes. No novo contexto, houve a substituição da tradicional interação direta entre educador e educando pelas aulas não presenciais. Certamente, para isso se concretizar, foi necessário que as redes de ensino oferecessem suporte tecnológico e material adequado às atividades.

Mesmo tendo que realizar as atividades de ensino remotamente, uma parcela dos respondentes informou não ter recebido nenhum tipo de suporte para a realização das aulas. Circunstância mais desfavorecida foi a dos professores das redes municipais, tendo sido registrados $14,4 \%$ dos respondentes que afirmaram não ter contado com nenhum suporte, em comparação aos 7,1\% dos profissionais das redes estaduais.

O tipo de assistência varia entre as redes de ensino. Algumas alternativas possuem menor custo, como fornecer materiais impressos ou disponibilizar apoio pedagógico para professores e/ou estudantes. Outras estratégias podem custar bem mais, como a disponibilização de aulas por TV ou rádio e a utilização das plataformas ou aplicativos pedagógicos, também denominados ambientes virtuais de aprendizagem.

Um dos motivos de as redes estaduais oferecerem mais suporte para a realização do ensino remoto é que elas contam com um quantitativo maior de profissionais, o que pode significar maior capacidade de investimentos. Dessa forma, é esperado que aos professores das redes estaduais seja oferecido mais suporte institucional, sobretudo recursos tecnológicos mais caros. 
Chama a atenção o fato de que, considerando somente os professores das redes estaduais, existe uma disparidade na disponibilização dos recursos tecnológicos de maior valor quando se comparam as regiões geográficas do Brasil. Primeiro, fica latente o fato de os professores de regiões que mais contam com ambientes virtuais de aprendizagem também possuem mais aulas realizadas por TV ou rádio e vice-versa (Gráfico 1). Em seguida, é possível identificar a persistência das desigualdades regionais também em relação ao suporte oferecido pelas redes de ensino para a realização de aulas não presenciais. Nessa lógica, é sabido que os respondentes que atuavam no Sul e no Sudeste do Brasil tiveram maior suporte institucional nessas tecnologias do que aqueles que se encontravam nas regiões Nordeste e Norte.

\section{Gráfico 1: Associação entre os percentuais de professores das Redes}

\section{Estaduais de Ensino com Ambiente Virtual de Aprendizagem e} aulas por TV ou rádio, de acordo com a região geográfica - Brasil, 2020.

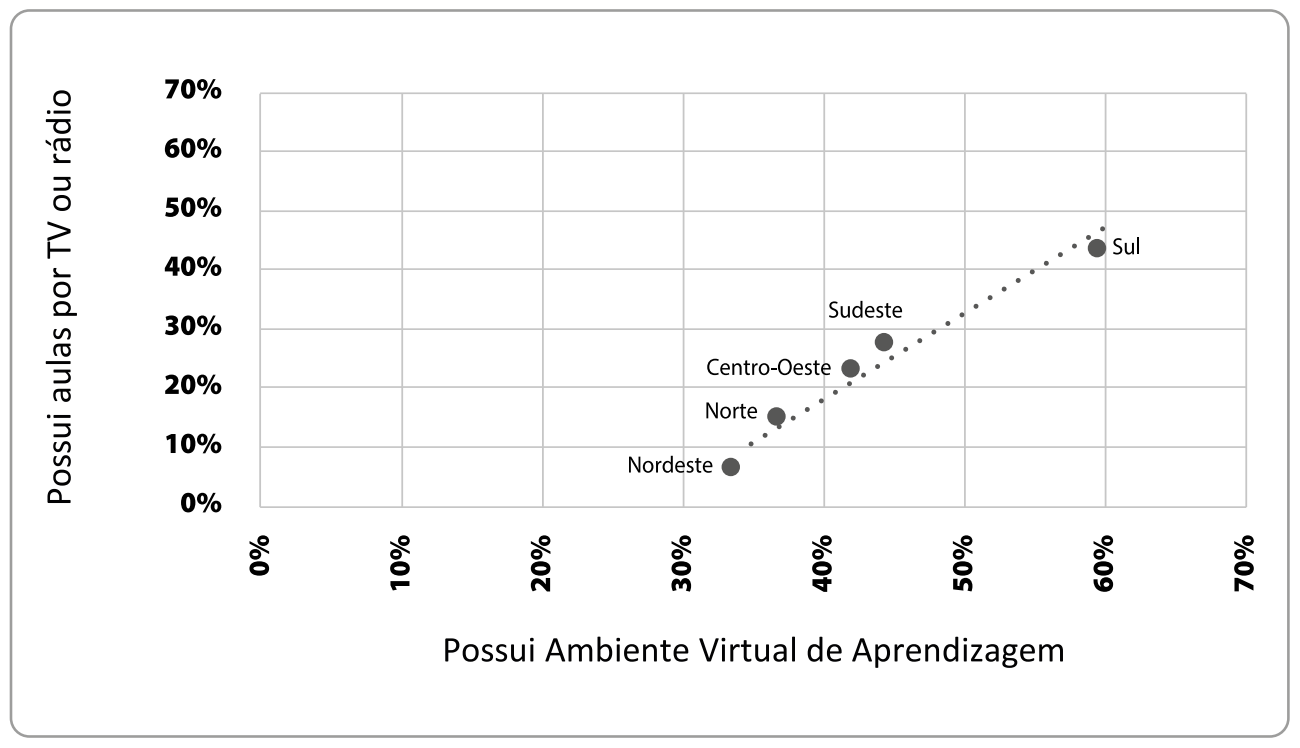

Fonte: Elaborado pelos autores com base nos dados da pesquisa Docência na Educação Básica em Tempos de Pandemia (GESTRADO, 2020).

\section{Recursos disponíveis}

O novo ambiente de ensino exige que professores e alunos possuam recursos tecnológicos para realizar as atividades. Enquanto os docentes precisam de ferramentas para preparar as aulas e fazê-las chegar aos estudantes, estes necessitam de recursos tecnológicos para acessar os conteúdos disponibilizados. 
Outro aspecto importante é que os estudantes possuem bem menos acesso a recursos tecnológicos necessários ao ensino remoto do que os professores. A parcela de professores que não os possuem é de 17,4\%, ao passo que atinge 66,2\% entre os estudantes (Gráfico 2). Em outras palavras, cerca de dois em cada três estudantes não dispõem de recursos tecnológicos para acompanhar as aulas a distância.

Merece mencionar que tais resultados se referem à percepção exclusiva dos professores, que foi o público-alvo da pesquisa. Isto é, eles responderam sobre o fato de eles próprios possuírem recursos tecnológicos para as atividades de ensino remoto e em relação à visão acerca dos estudantes que tinham os recursos.

A disparidade do acesso a recursos tecnológicos entre professores e estudantes foi comum a todas as regiões geográficas do Brasil (Gráfico 2). A indisponibilidade de recursos pelos professores foi maior na região Norte, tendo sido registrados $22,2 \%$ dos participantes nessa situação. A melhor situação dos estudantes foi encontrada no Centro-Oeste, que teve a menor taxa de indisponibilidade de recursos tecnológicos $(59,2 \%)$.

\section{Gráfico 2: Percepção dos professores sobre a indisponibilidade de recursos de alunos e professores da Educação Básica para realizar as aulas não presenciais de acordo com a região geográfica - Brasil, 2020}

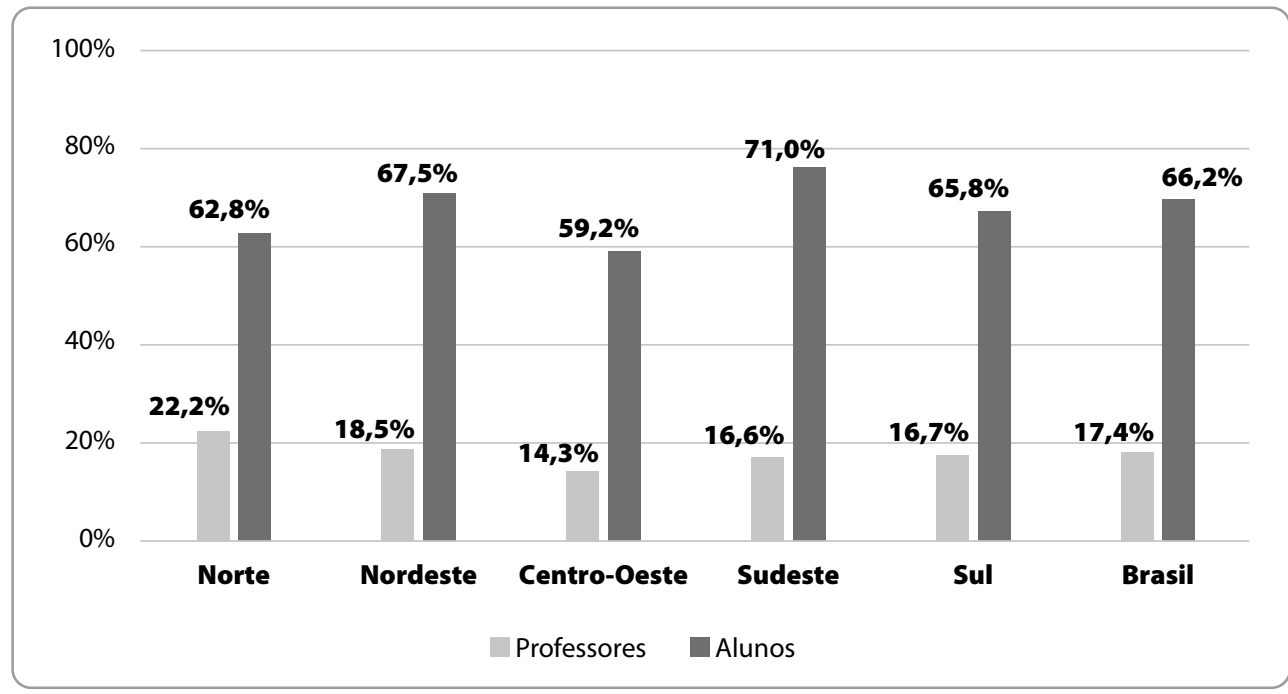

Fonte: Elaborado pelos autores com base nos dados da pesquisa Trabalho Docente em Tempos de Pandemia (GESTRADO, 2020).

\section{Sobrecarga de trabalho e participação dos estudantes}

O desenvolvimento de atividades de ensino remotas acarretou formas diferentes de trabalho e demandou novas habilidades dos professores. O que se espera é que o novo 
contexto de ensino consiga fazer com que os estudantes participem das atividades e, consequentemente, aprendam os conteúdos repassados.

Os resultados mostram que a grande parte dos participantes, o equivalente a $82,4 \%$, afirmou que aumentou a quantidade de horas de trabalho destinadas à preparação das aulas não presenciais (Gráfico 3). Ao mesmo tempo, somente 5,3\% dos professores afirmaram ter diminuído a quantidade de tempo gasto nessas atividades. Trata-se de uma informação de extrema relevância, pois mostra que os docentes passaram a assumir maior carga de trabalho para realizar o ensino de forma remota. Um dos possíveis fatores que contribui para o aumento da carga de trabalho é a pouca ou insuficiente formação dos profissionais para lidar com tecnologias digitais. Os ambientes virtuais de aprendizagem ainda não são conhecidos pela maioria dos profissionais em exercício presencial nas escolas.

Outro fato desejado em relação às atividades de ensino, seja ele presencial ou a distância, é que os estudantes participem delas. Os resultados apontaram para uma constatação negativa sobre o ensino remoto, pois $83,9 \%$ dos professores afirmaram que houve diminuição da participação dos estudantes nas atividades propostas (Gráfico 3). Somente 3,6\% dos participantes perceberam que aumentou a participação dos estudantes nas atividades com a utilização do ensino remoto.

\section{Gráfico 3: Distribuição dos professores de acordo com a quantidade de horas de trabalho destinadas à preparação das aulas não presenciais e a participação dos estudantes nas atividades propostas - Brasil, 2020.}

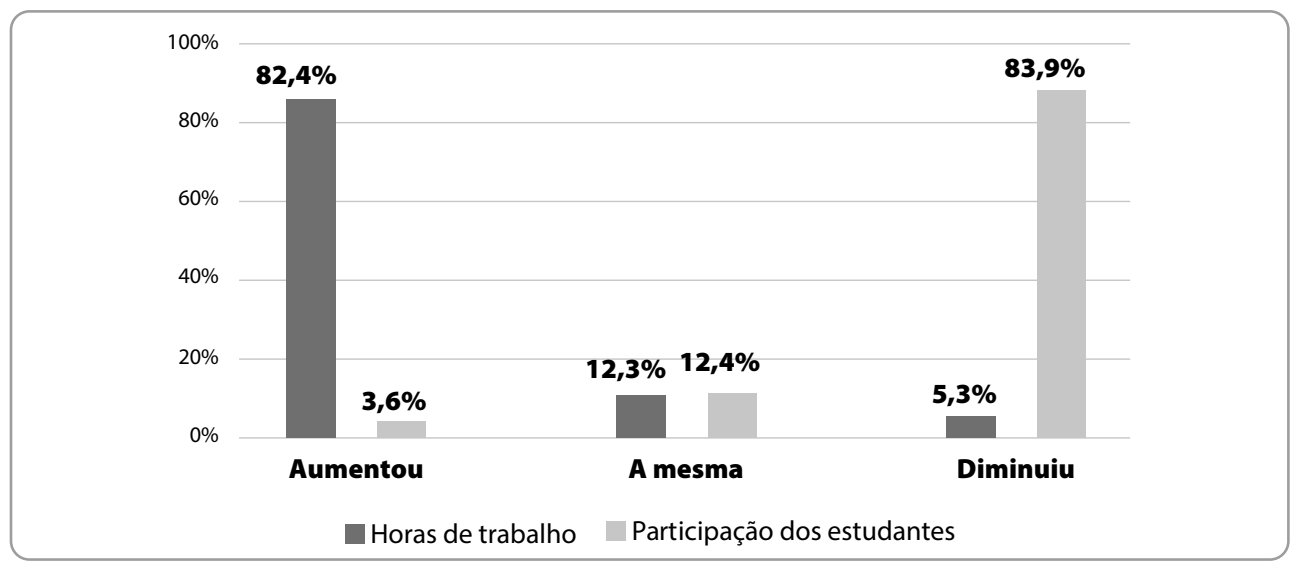

Fonte: Elaborado pelos autores com base nos dados da pesquisa Trabalho Docente em Tempos de Pandemia (GESTRADO, 2020).

A ausência de recursos tecnológicos, a falta de ambiente reservado para estudo, além da disponibilidade de computador e conexão de internet podem comprometer cabalmente 
a participação dos estudantes, mesmo os mais interessados. Diferentemente da sala de aula, foge ao controle do professor a capacidade de concentração dos alunos para evitar que eles se dispersem nos ambientes virtuais. Certamente, os professores necessitam incrementar as atividades de forma a atrair a atenção dos alunos.

De forma geral, esses foram alguns dos aspectos investigados sobre o desenvolvimento das atividades de ensino não presenciais pelos professores das redes públicas de educação básica. Outros resultados também foram divulgados (GESTRADO, 2020b), com destaque para os artigos que compõem este dossiê. Além disso, outras produções acadêmicas têm sido e serão desenvolvidas pela equipe de pesquisadores do Gestrado.

\section{Considerações finais}

O distanciamento social em decorrência da pandemia comprometeu a rotina de milhões de crianças e jovens e de suas famílias em todo o mundo. Constata-se, no campo das políticas educacionais, que, apesar do muito que se tratou nas últimas décadas sobre as reformas educacionais para a sociedade do século XXI, a dita "sociedade do conhecimento", nenhum sistema educativo estava preparado para enfrentar essa excepcionalidade, principalmente em países que apresentam fragilidades gritantes na oferta educativa, como é o caso do Brasil.

As redes de ensino no País se viram forçadas a suspender as aulas presenciais, sob pena de uma tragédia ainda maior, visto a precariedade do sistema público de saúde. Desde então, gestores e profissionais da educação têm se desdobrado para encontrar alternativas para realizar as atividades de ensino de forma remota. Na maioria das situações, o que se observou foi a migração direta do ambiente presencial para o virtual, sem o suporte técnico necessário e sem qualquer planejamento prévio. Com isso, instaura-se um debate que transcende o setor educacional, pois a suspensão das aulas presenciais altera a rotina dos estudantes e de suas famílias, coloca restrições às mães trabalhadoras que terão de arcar com o cuidado integral de seus filhos e impõe novas condições de trabalho para os docentes e de estudos para os alunos.

Assistimos também a uma grande ansiedade por parte dos gestores públicos em tentar resgatar a normalidade ou garantir que o ensino se realize a qualquer custo. A preocupação deles é cumprir o programa curricular previsto para o ano letivo, pois encontram-se submetidos às pressões próprias do modo de regulação da educação brasileira, extremamente dependente das avaliações externas, em especial do Índice de Desenvolvimento da Educação Básica (Ideb).

Esse debate tem ocupado importante espaço nos meios de comunicação e ensejado novos estudos e pesquisas. Do que se conhece até o momento, é possível afirmar que a pandemia não só colocou em evidência as já conhecidas desigualdades sociais, raciais, 
regionais e educacionais que o País comporta, como também tem aprofundado as disparidades entre as classes sociais e aumentado o fosso entre ricos e pobres.

A situação é complexa e desafiadora, envolve desde a falta de acesso e suporte tecnológico dos profissionais e dos estudantes, a pouca experiência dos professores e a falta de capacitação prévia para o uso de tecnologias para a realização do trabalho remoto, até a situação vulnerável de muitas famílias de estudantes.

Diante desse cenário, sabemos que o recurso à pesquisa pode ajudar a encontrar caminhos menos tortuosos para se chegar a um futuro mais promissor, já que o presente tem sido, muitas vezes, desesperador. Além do conhecimento científico, é imprescindível o envolvimento dos sujeitos implicados nesse contexto. $\mathrm{O}$ diálogo com as comunidades escolares, envolvendo os estudantes e suas famílias, os profissionais da educação e suas representações sindicais, é o único meio de o poder público encontrar caminhos para seguir adiante, respeitando os limites e as condições que a situação impõe.

Recebido em: 25/10/2020 e Aprovado em: 12/11/2020

\section{Referências}

BABBIE, Earl. The Practice of Social Research. 10. ed. Belmont: Wadsworth/Thompson Learning, 2004.

FCC. Fundação Carlos Chagas. Educação escolar em tempos de pandemia: Informe $n^{0}$ 1. São Paulo, 2020.

GESTRADO. Grupo de Estudos Sobre Política Educacional e Trabalho Docente. Base de dados. Trabalho Docente em Tempos de Pandemia. Belo Horizonte: UFMG, 2020.

GESTRADO. Grupo de Estudos Sobre Política Educacional e Trabalho Docente. Relatório Técnico. Trabalho Docente em Tempos de Pandemia. Belo Horizonte: UFMG, $2020 \mathrm{~b}$.

INSTITUTO PENÍNSULA. Sentimento e percepção dos professores brasileiros nos diferentes estágios do coronavírus no Brasil: Relatório de Pesquisa. 2020.

OLIVEIRA, Dalila Andrade. Políticas conservadoras no contexto escolar e autonomia docente. Práxis Educativa, Ponta Grossa, v. 15, e2015335, 2020.

PAIVA, Vanilda. Pesquisa educacional e decisão política. In: WARDE, M. J. (Org.). Novas políticas educacionais: críticas e perspectivas. São Paulo: PUC-SP, 1998, p. 125-138.

PNUD. Programa das Nações Unidas para o Desenvolvimento. Relatório do Desenvolvimento Humano 2019. Nova Iorque: PNUD, 2019.

XIMENES, D.; AGATTE, J.P. A gestão das condicionalidades do Programa Bolsa Família: uma experiência intersetorial e federativa. Inclusão Social, Brasília, v. 5, n. 1, p.11-19, jul./dez. 2011. 